\title{
Determinants of COVID-19 Prevention Behavior in the Elderly in Urmia: Application of Health Belief Model
}

\author{
Morad Ali Zareipour ${ }^{1}$, Mojtaba Fattahi Ardakani ${ }^{2}$, Monireh Rezaee Moradali ${ }^{3}$, Mohammad Saeed Jadgal ${ }^{4}$, Ehsan Movahed $^{5 *}$ \\ ${ }^{1}$ Health System Research Unit, Health Center of Urmia, Urmia University of Medical Sciences, Urmia, Iran; ${ }^{2}$ Diabetes \\ Research Center, Shahid Sadoughi University of Medical Sciences, Yazd, Iran; ${ }^{3}$ Student Research Committee, Midwifery and \\ Reproductive Health Research Center, School of Nursing and Midwifery, Shahid Beheshti University of Medical Sciences, \\ Tehran, Iran; ${ }^{4}$ Department of Public Health, Medical School, Iranshahr University of Medical Sciences, Iranshahr, Iran; ${ }^{5}$ School \\ of Public Health, Jiroft University of Medical Sciences, Jiroft, Iran
}

Edited by: Sasho Stoleski Citation: Zareipour M, Ardakani MF, Moradali MR, Jadgal MS, Movahed E. Determinants of COVID-19 Prevention Behavior in the Elderly in Urmia: Application of Health Belief Model. Open Access Maced J Med Sci. 2020 Dec 25; 8(T1):646-650 https://doi.org/10.3889/oamjms.2020.565 Keywords: Prevention; Elderly; Health belief model; *Correspondence: Ehsan Movahed Sch COVID-19 Health, Jiroft University of Medical Sciences, Jiroft, Iran. E-mail: ehsanmovahed89@yahoo Received: 22-Nov-2020 Revised: 05-Dec-2020 Accepted: 10-Dec-2020 Copyright: @ 2020 Morad Ali Zareipour, attahi Ardakani, Monireh Rezaee Moradal, Mohammad Saeed Jadgal, Ehsan Movahed
Funding: Publication of this article was financially pported by the Scientific Foundation SPIROSKI, Skopje, Republic of Macedonia Competing Interests: The authors have declared that no
competing interests exist.
Open Access: This is an open-access article distributed under the terms of the Creative Commons Attribution-

\begin{abstract}
BACKGROUND: COVID-19 disease effects on all age group and sex, especially the elderly, due to the high mortality rate, it is very impressive and the protective measures can reduce mortality in the elderly.

AIM: The present study was conducted to find the determinants of COVID-19 prevention behavior in the elderly in Urmia by emphasizing on the health belief model.

METHODS: The present study was a cross-sectional study on 1400 elderly people in Urmia, Iran in 2020 and the sample selection was by simple random sampling by simple random sampling. The data collection tool was a researcher-made questionnaire in this study that included demographic characteristics, health belief mode questionnaire, and COVID-19 prevention behaviors. Data were analyzed using ANOVA and linear regression tests using SPSS 23 software.

RESULTS: The results showed that the COVID-19 prevention behavior score has been increased by increasing age rate and this behavior was higher in older women than men $(p=0.02)$. Furthermore, linear regression test showed the most predictive constructs as knowledge $(B=0.38)$, perceived susceptibility $(B=0.29)$, perceived intensity $(B=0.25)$, and perceived self-efficacy $(B=0.21$, respectively) and these structures were statistically significant $(p<0 / 05)$.

CONCLUSION: Effective interventions based on the health belief model and emphasizing on promoting knowledge perceived susceptibility, severity, and perceived self-efficacy can prevent the elderly from developing this disease and its complications.
\end{abstract}

\section{Introduction}

The COVID-19 pandemic disease has devastated the global economy and financial markets, and it forced the governments to take drastic public health measures to decrease the effects of the disease [1]. The virus has caused panic throughout the world and has affected on all age and sex groups. Elderly are one of the most at risk groups and according to epidemiologists, age is the most important factor in reducing the survival of COVID-19, especially after 65 years [2], [3]. Thus, targeting the elderly and try to persuade them to follow public health precautions are the strategies of governments around the world [4]. According to the high mortality rate among the elderly and the clear goal of governments around the world, it is only reasonable to expect elderly to be more conscientious than young people in preventing COVID-19. However, the results of the Daoust's study in 27 countries were unfortunately alarming and worrying in 2020, and despite the fact that elderly are much more likely to die from COVID-19 disease than other age groups, they are less likely to follow preventative guidelines such as staying at home [5].

Poor preventive measures in the elderly show that, they do not understand about the importance of the issue and do not think about COVID-19 disease as a threat to their health. Determinants and affecting factors on the preventive behavior of the disease must be identified to find preventive measures and control of COVID-19 disease [6]. Evidence also suggests that identifying determinants and protective measures as effectively and accurately as possible requires the use of patterns and theories of behavior change [7]. One of the models which were used to prevent the disease is the Health Belief Model (HBM). The HBM model is a well-accepted psychosocial model for behavior change and is used to describe the relationship between belief and behavior. HBM assumes that people's involvement in the prevention, early detection, and treatment of related measures to a particular health problem depends on their understanding in which they are at risk of the disease even if they do not suffer from its 
symptoms perceived susceptibility). Moreover, they should know that the disease is a health problem which can lead serious complications (perceived severity); they should believe that the benefits of the proposed preventive measures (perceived benefits) are more than the anticipated barriers (perceived barriers). In addition, they should believe that they are motivated and able to lead a healthy lifestyle and the capacity to do protective behaviors (self-efficacy). In addition, HBM hypothesizes that guidance for action can increase interaction in preventive behavior as an internal and external behavioral stimulus [8], [9].

According to the necessity of performing protective behaviors against COVID-19 infection and strict observance of health protocols among the elderly, the determinants of COVID-19 prevention behavior among these groups in designing and implementing appropriate educational interventions to promote protective behaviors are promising the beneficial effects. Therefore, considering the role of HBM model in preventing behaviors that protect against disease, the present study was conducted to find the determinants of COVID-19 prevention behavior in the elderly in Urmia with emphasis on the health belief model.

\section{Materials and Methods}

\section{Study design and population}

This cross-sectional study was conducted to investigate the determinants of coronavirus (COVID19) prevention in the elderly based on the health belief model in health centers in Urmia, Iran in 2020.

\section{Study tool}

Data collection tools in this study were a researcher-made questionnaire that included demographic characteristics of the subjects, coronavirus knowledge questionnaire, coronavirus prevention behaviors questionnaire, and health belief model questionnaire.

Knowledge assessment was in the form of 16 questions, which was prepared in the form of "Yes", "I do not know", options, the "Yes always" option was given a score of 2, the "I do not know" option was given a score of 1 , and the "No" option was given a score of 0 . Scores of knowledge questionnaire range from zero to 32. Questions and scores of health belief model structures is based on the Likert scale of five options (strongly agree, agree, have no opinion, disagree, strongly disagree) that the score of "totally agree" option is 5 and the score of "strongly disagree" option is 1 . Each structure had 6 questions and minimum and maximum scores were $6-30$ points. 12 questions with three options "always," "sometimes," "never" were used to assess COVID-19 prevention behavior. The score of "always" option was 2 points, the score of "sometimes" option was 1 point, and the score of "never" option was 0 point. Scores for coronavirus prevention behavior questions range from zero to 24

\section{Validation and pilot study}

The items of each desired outcomes were selected by reviewing the literature and for the validity and reliability of these questionnaires, content validity methods, and Cronbach's alpha test were used, respectively, it was sent to 10 health education specialists and geriatrician to find the validity of the questionnaire. Based on the opinions of these experts, the necessary amendments were made to the questionnaire. The validity of the questionnaire was higher than $80 \%$. To measure reliability, the questionnaire was completed by 30 elderly people who were not part of the intervention and control group, and reliability coefficient of knowledge questions 0.76 , perceived susceptibility 0.77 , perceived severity 0.80 , comprehension barriers 0.81 , guideline for action 0.84 perceived benefits 0.86 , and self-efficacy 0.78 coronavirus prevention behavior was calculated 0.73 using Cronbach's alpha test.

\section{Data collection}

Healthcare providers contacted elderly families by telephone, and the study goals were explained to all participants in the study. The questionnaires were then completed by telephone interview for the elderly. Inclusion criteria were age group over 60 years, ability to answer by phone, non-resident of nursing home, and exclusion criteria were the dissatisfaction and unwillingness to continue answering the questionnaires.

\section{Sampling}

According to the elderly population of Urmia ( 51,000 people), $2.8 \%$ of this population was considered as the study population which about 1,400 people entered the study. By simple random sampling method, $2.8 \%$ of the elderly were selected from 30 health centers in Urmia in proportion to the population of each health center.

\section{Statistical analysis}

Descriptive statistical methods were used to summarize data on sociodemographic characteristics. Data were summarized as frequencies ( $n$ ) and percentages (\%) for categorical variables. The ANOVA tests were used to find the relation between mean COVID-19 prevention behavior and sociodemographic 
variables. In the case of a significant ANOVA test, post hoc analysis (LSD) was performed for multiple comparisons between each two categories. Furthermore, the linear regression test was used to predict coronavirus prevention behavior in the elderly. All data analyses were performed using Statistical Package for the Social Sciences (SPSS) software, version 23.

\section{Results}

The mean age of the elderly was 66. $6 \pm$ 4.97 years. The highest age group was in the age group of $60-65(33 \%)$. Most of the elderly were housewives $(49 \%)$ and marital status indicates that most of the elderly in the study were married $(70 \%)$. Furthermore, most of the elderly were illiterate in terms of education (51\%). In terms of economic situation, most of the elderly had poor economic status (41.5\%). The elderly suffered from chronic disease were $72.5 \%$ (cardiovascular, respiratory, diabetes, and hypertension) (Table 1).

Table 1: Frequency and percentage of distribution of demographic characteristics of the studied elderly

\begin{tabular}{lll}
\hline Variables & Number & Percent \\
\hline Age & & \\
$60-65$ & 462 & 33 \\
$65-70$ & 420 & 30 \\
$70-75$ & 350 & 25 \\
$80-75$ & 168 & 12 \\
Sex & & \\
Male & 686 & 49 \\
Female & 714 & 51 \\
Job & & \\
Housewife & 686 & 49 \\
Employed & 224 & 16 \\
Retired & 420 & 30 \\
Out of work & 70 & 5 \\
Marital status & & \\
$\quad$ Married & 980 & 70 \\
Single & 196 & 14 \\
Divorced/widow & 224 & 16 \\
Education & & \\
Illiterate & 714 & 51 \\
$\quad$ Elementary & 490 & 35 \\
Diploma and Postgraduate & 196 & 14 \\
History of chronic diseases & & 72.5 \\
$\quad$ Yes & 1015 & 27.5 \\
$\quad$ No \\
The economic situation & 385 & 41.5 \\
Weak & & 36.7 \\
Moderate & 581 & 21.8 \\
$\quad$ Good & 514 & \\
\hline
\end{tabular}

The results of ANOVA test showed that the score of COVID-19 prevention behavior increased by increasing age and this difference was significant $(p=0.02)$. Furthermore, in women, the COVID-19 prevention behavior score was higher than men and was statistically significant $(p=0.03)$. On the other hand, the score of COVID-19 prevention behavior in single elderly (single, divorced/deceased spouse) was lower than married elderly $(p=0.04)$. Another result of the study indicates that people who have at least one chronic disease (cardiovascular, respiratory, diabetes, hypertension, etc.) have a more unfavorable preventive behavior than other people $(p=0.01)$ (Table 2$)$.
Table 2: Demographic information and its relationship with COVID-19 prevention behavior in the studied elderly

\begin{tabular}{lll}
\hline Variables & $\begin{array}{l}\text { Mean and standard deviation of } \\
\text { COVID-19 preventive behavior score }\end{array}$ & p-value \\
\hline Age & $16(1.8)$ & $0.02^{*}$ \\
$60-65$ & $15(2.7)$ & \\
$65-70$ & $16(2.2)$ & \\
$70-75$ & $18.4(2.4)$ & $0.03^{*}$ \\
$<75$ & $15.8(3.9)$ & \\
Sex & $18.2(38)$ & 0.2 \\
$\quad$ Male & $16.2(4.2)$ & \\
Female & $15.6(2.1)$ & \\
Job & $16.5(1.7)$ & $0.04^{*}$ \\
Housewife & $15.8(28)$ & \\
Self-employed & & \\
Retired & $18.4(2.6)$ & 0.08 \\
$\quad$ Out of work & $16.6(1.3)$ & \\
Marital status & $15.8(3.1)$ & \\
$\quad$ Married & & \\
$\quad$ Divorced & $16.39(2.9)$ & \\
$\quad$ Widow/widower & $17.73(3.3)$ & \\
Education & $17.9(2.1)$ & \\
Illiterate & $16.4(1.7)$ & \\
$\quad$ Elementary & & \\
Junior & $15.1(2.1)$ & \\
$\quad$ Diploma and Postgraduate & & \\
History of diseases chronic & $18.8(3.5)$ & \\
Yes & $17.2(3.1)$ & \\
$\quad$ No & $15.6(2.3)$ & \\
The economic situation & $16.8(3.2)$ & \\
$\quad$ Weak & & \\
Moderate & & \\
Good & & \\
\hline
\end{tabular}

According to the linear regression test to predict coronavirus prevention behavior in the elderly, respectively, the most predictive construct was knowledge $(B=0.38)$, the second construct was perceived susceptibility $(B=0.29)$, and the third construct was perceived severity $(B=0.25)$ and the fourth construct was perceived self-efficacy $(B=0.21)$ and these constructs of the health belief model are statistically significant in predicting the coronavirus prevention behavior of the elderly $(p<0.05)$ (Table 3$)$.

Table 3: Findings of linear regression model in predicting COVID-19 preventive behaviors in the elderly

\begin{tabular}{llllll}
\hline Independent variables & $\begin{array}{l}\text { (regression } \\
\text { coefficient) }\end{array}$ & SE & Beta & $t$ & $p$-value \\
\hline Knowledge & 0.38 & 0.097 & 0.32 & 3.961 & 0.001 \\
Perceived susceptibility & 0.29 & 0.087 & 0.18 & 2.6 & 0.02 \\
Perceived severity & 0.25 & 0.085 & 0.16 & 2.5 & 0.03 \\
Perceived benefits & 0.04 & 0.045 & 0.06 & 1.21 & 0.7 \\
Perceived barriers & -0.02 & 0.07 & -0.09 & 2.02 & 0.6 \\
Cues to action & 0.06 & 0.08 & 0.07 & 1.05 & 0.9 \\
Perceived self-efficac & 0.21 & 0.083 & 0.15 & 2.15 & 0.04 \\
\hline
\end{tabular}

\section{Discussion}

The results showed that elderly had higher disease prevention behavior. In fact, these people thought about the COVID-19 threat and believed that the threat was related to them. According to the $\mathrm{WHO}$, elderly are at higher risk of the disease [10]. Iran's media and health care system provide significant programs to show that the risk of elderly is too high about the disease. This may have led elderly to learn that they are more susceptible to the disease and should consider more on preventive behavior.

In this study, it was found that older women had better COVID-19 prevention behaviors than men. 
The results of Bell et al.'s study (2005) showed that women with diabetes had better self-care behaviors than men [11]. Gender differences in disease prevention behaviors can be derived from differences in knowledge, perceived susceptibility, and perceived severity of the disease and its duration, as well as the other diseases in men and women [12]. On the other hand, the results showed that there is a significant relationship between marital status and COVID-19 prevention behavior in the elderly. So that disease prevention behavior is more in married elderly. These results are consistent with the results of the study of Seow et al. that divorced and single people had uncontrolled hypertension [13]. Adoption of disease-preventing behaviors is more common among people who are in daily contact with their partner, and these behaviors are mostly through direct social control such as reminding, encouraging, monitoring, or even threatening [14], [15]. Furthermore, the existence of social support such as family can play an effective role in adopting preventive behaviors among the elderly.

The study found that people with at least one chronic illness (cardiovascular, respiratory, diabetes, or high blood pressure) had poorer preventive behaviors than others. This unfavorable attitude toward the prevention of this disease can indicate that these people are more at risk. Jahangiry et al. showed that people who did not have any chronic disease were more sensitive and had efficacy than those with a history of chronic disease, and their fear of COVID-19 was higher [16]. It can be considered that people who have an underlying disease, due to a more unfavorable attitude than other people, have a denial of a severe disease in themselves and believe that severely occurring this disease in them is less. The results of linear regression showed that there is a statistically significant relationship between the four variables of knowledge, perceived susceptibility, perceived severity, and perceived self-efficacy with the variable of coronavirus prevention behavior.

Knowledge structure was the most predictive of COVID-19 prevention behavior. Elderly people with high knowledge of COVID-19 had more coronary preventive behaviors. The study of Mahmoodabad et al. [17] showed that there was a significant correlation between knowledge and prevention behavior of falls in the elderly. An effective step can be taken in the prevention of this disease by increasing knowledge of the disease and ways of transmission, ways of prevention and affecting factors on COVID-19 disease. However, studies have shown that preventive behaviors cannot be improved by increasing knowledge alone. Therefore, to meet longterm self-care, creating attitudes and motivating people is more important than knowledge alone [18], [19].

In the present study, there was a significant relationship between perceived susceptibility variable and COVID-19 prevention behavior. High perceived susceptibility of people seems to lead to better performance in performing preventive behaviors. Raamkumar emphasized the role of perceived susceptibility in maintaining physical distance during COVID-19 outbreaks [20]. The high perceived susceptibility of the people indicates that they believe they are at higher risk of the disease. Therefore, the presence of this high perceived susceptibility will cause them to take the lead in performing preventive behaviors. The results show that there is a significant relationship between perceived intensity constructs and COVID-19 prevention behavior variable. This can be due to the knowledge of serious risks such as shortness of breath and extreme fatigue, neurological problems, including dizziness and impaired sense of smell and taste, the possibility of renal infarction and consequently the possibility of irreversible damage to other organs, brain dysfunction, stroke, or meningitis is one of the most important factors in raising the level of perceived severity in this regard. A study by Lin et al. showed that there is a significant relationship between the severity and perceived threat of AIDS and the reduction of high-risk behaviors [21]. Therefore, if the elderly are aware of the complications of COVID-19 and they fear that they may have these complications after contracting the disease; most of them will follow COVID-19 prevention behaviors.

Self-efficacy is a person's judgment of his or her ability to prevent COVID-19. In the present study, self-efficacy was one of the predictors of disease prevention behavior, which is consonant with Conn's study in which that self-efficacy was considered as the most important predictor of physical activity in the elderly [22] and with the study of Mahmoodabad et al. in which self-efficacy has been mentioned as a reason in promoting fall prevention behavior [17]. It seems that the elderly should work to improve their self-efficacy in adopting COVID-19 prevention behaviors.

\section{Conclusions}

The promotion of knowledge, perceived susceptibility, severity, and perceived self-efficacy can prevent the elderly from developing this disease and its complications. We recommend that careful educational planning for the elderly was strong predictors of COVID19 prevention behavior which it was based on the health belief model on the structures of knowledge, perceived susceptibility and perceived severity and perceived self-efficacy to prevent the elderly from contracting this disease and its complications.

\section{Limitations of the Study}

The distribution of the survey through the phone allowed only those who can answer and have 
phone access to take part. This represents a major limitation of this study.

\section{Ethical Considerations}

All procedures performed in studies involving human participants were in accordance with the ethical standards of the institutional and/or national research committee and with the 1964 Helsinki Declaration and its later amendments or comparable ethical standards. The study was approved by the ethics committee of the Islamic Azad University with code (IR.IAU.TABRIZ. REC.1399.110).

\section{References}

1. World Health Organization. Coronavirus Disease 2019 (COVID-19): Situation Report No. 72. Geneva: World Health Organization; 2020.

2. Zhou F, Yu T, Du R, Fan G, Liu Y, Liu Z, et al. Clinical course and risk factors for mortality of adult inpatients with COVID-19 in Wuhan, China: A retrospective cohort study. Lancet. 2020;395(10229):1054-62. https://doi.org/10.1016/ s0140-6736(20)30566-3

PMid:32171076

3. Zareipour MA, Sadaghianifar A, Aghziyarat NA, Azari MT, Moradali MR. Investigating the causes of elderly people leaving home during Coronavirus disease-19 epidemic. Open Access Maced J Med Sci. 2020;8(T1):548-52. https://doi.org/10.3889/ oamjms.2020.5553

4. Utych SM, Fowler L. Age-based messaging strategies for communication about COVID-19. J Behav Public Adm. 2020;3(1):1-14. https://doi.org/10.30636/jbpa.31.151

5. Daoust JF. Elderly people and responses to COVID-19 in 27 countries. PLoS One. 2020;15(7):e0235590. https://doi. org/10.1371/journal.pone.0235590 PMid:32614889

6. Xiang YT, Yang Y, Li W, Zhang L, Zhang Q, Cheung T, et al. Timely mental health care for the 2019 novel Coronavirus outbreak is urgently needed. Lancet Psychiatry. 2020;7(3):2289. https://doi.org/10.1016/s2215-0366(20)30046-8 PMid:32032543

7. Fathi $\mathrm{Y}$, Barati $\mathrm{M}$, Zandiyeh $\mathrm{M}$, Bashirian S. Prediction of preventive behaviors of the needlestick injuries during surgery among operating room personnel: Application of the health belief model. Int J Occup Environ Med. 2017;8(4):232-40. https://doi. org/10.15171/ijoem.2017.1051

PMid:28970598

8. Ghanbary MK, Shamsi M, Khorsandi M, Farazi A, Ranjbaran M, Eshrati B. Effect of training with teaching methods designed based on health belief model on knowledge and self-efficacy in nurses on the disciplines standard precautions in hospitals. $J$ Hum Health. 2015;1(2):51.

9. Phillips JC. Caring for the vulnerable: Perspectives in nursing theory, practice, and research. J Cultur Divers. 2005;12(4):161.
10. Heidari A, Eghbal F. Relationship between difficulties in emotional regulation, intimacy, attachment styles and marital satisfaction in couples in steel industry of Ahvaz. New Find Psychiatry. 2010;5(15):115-34.

11. Bell RA, Arcury TA, Snively BM, Smith SL, Stafford JM, Dohanish $\mathrm{R}$, et al. Diabetes foot self-care practices in a rural triethnic population. Diabetes Educ. 2005;31(1):75-83. https:// doi.org/10.1177/0145721704272859 PMid: 15779248

12. Beker J, Belachew T, Mekonin A, Hailu E. Predictors of adherence to self-care behaviour among patients with chronic heart failure attending Jimma University Specialized Hospital chronic follow up clinic, South West Ethiopia. J Cardiovasc Dis Diagn. 2014;2(6):1-8. https://doi.org/10.4172/2329-9517.1000180

13. Seow LS, Subramaniam M, Abdin E, Vaingankar JA, Chong SA Hypertension and its associated risks among Singapore elderly residential population. J Clin Gerontol Geriatr. 2015;6(4):12532. https://doi.org/10.1016/j.jcgg.2015.05.002

14. Umberson D. Gender, marital status and the social control of health behavior. Soc Sci Med. 1992;34(8):907-17. https://doi. org/10.1016/0277-9536(92)90259-s PMid: 1604380

15. Lim YM, Sung MH, Joo KS. Factors affecting healthpromoting behaviors of community-dwelling Korean older women. J Gerontol Nurs. 2010;36(10):42-50. https://doi. org/10.3928/00989134-20100504-05 PMid:20506936

16. Jahangiry L, Bakhtari F, Sohrabi Z, Reihani $P$, Samei $S$, Ponnet K, et al. Risk perception related to COVID-19 among the Iranian general population: An application of the extended parallel process model. BMC Public Health. 2020;20(1):1571. https://doi.org/10.21203/rs.3.rs-33493/v1 PMid:33076875

17. Mahmoodabad SS, Zareipour MA, Askarishahi M, Beigomi A prevention determinants of falling in the elderly citizens: A precaution adoption process model (PAPM) carried-out in Urmia, Iran. Ambient Sci. 2018;5:41-5. https://doi.org/10.21276/ ambi.2018.05.sp1.ta07

18. Oldroyd JC, Unwin NC, White M, Mathers JC, Alberti KG Randomised controlled trial evaluating lifestyle interventions in people with impaired glucose tolerance. Diabetes Res Clin Pract. 2006;72(2):117-27. https://doi.org/10.1016/j. diabres.2005.09.018 PMid:16297488

19. Imai S, Kozai H, Naruse Y, Watanabe K, Fukui M, Hasegawa G et al. Randomized controlled trial of two forms of selfmanagement group education in Japanese people with impaired glucose tolerance. J Clin Biochem Nutr. 2008;43(2):82-7. https:// doi.org/10.3164/jcbn.2008050

PMid:18818757

20. Raamkumar AS, Tan SG, Wee HL. Use of health belief modelbased deep learning classifiers for COVID-19 social media content to examine public perceptions of physical distancing: Model development and case study. JMIR Public Health Surveill. 2020;6(3):e20493. https://doi.org/10.2196/20493 PMid:32540840

21. Lin P, Simoni JM, Zemon V. The health belief model, sexual behaviors, and HIV risk among Taiwanese immigrants. AIDS Educ Prev. 2005;17(5):469-83. https://doi.org/10.1521/ aeap.2005.17.5.469

22. Conn VS. Older adults and exercise: Path analysis of selfefficacy related constructs. Nurs Res. 1998;47(3):180-9. https:// doi.org/10.1097/00006199-199805000-00009 PMid:9610652 